[Original Article]

Received January 21, 2017

Revised April 23, 2017

Accepted April 27, 2017

${ }^{\dagger}$ Corresponding author

(elee@kookmin.ac.kr)

ORCID

Kyoung Rok Shin

http://orcid.org/0000-0002-7354-1751

Eun-Jung Lee

http://orcid.org/0000-0002-9005-5886

This paper is supported in part by the faculty fund of Kookmin University.

This paper is a part of a master's thesis.

\section{The effect of consumers' needs for uniqueness and pursuit of clothing benefit on bespoke suit purchase intention amongst 20 30-year-old males}

\author{
Kyoung Rok Shin and Eun-Jung Lee ${ }^{\text {*† }}$ \\ Fashion Merchandising Major, Graduate School of Design, \\ Kookmin University, Korea \\ Dept. of Fashion Design, College of Design, Kookmin University, Korea ${ }^{*}$

\section{30대 남성 소비자의 독특성 욕구와 의복추구혜택이 비스포크 정장 구매 의도에 미치는 영향}

\author{
신 경 록·이 은 정 \\ 국민대학교 디자인대학원 패션머천다이징 전공 \\ 국민대학교 조형대학 의상디자인학과
}

\begin{abstract}
Modern men are much more interested in their appearance than ever before, as well as showing an increased need for uniqueness in order to construct their own sphere and pursue differentiation from others. Besides, changes in life style and the aesthetic sense are causing men to pursue various kinds of clothing benefits so that they want a suit with characteristics beyond the stereotyped design and style. They have started to be actively engaged in clothing purchases, forming a driving force for the growth of the male suit market. Hence, this study has significance in that it offers data conducive to consumers' custom suit purchase by reviewing data on the present condition of the custom suit market and bespoke suits. In addition, it aims to give a summary on the theoretical bases of preceding studies, including the need for uniqueness, pursuit of clothing benefit and concern for the appearance of male consumers, as well as examining the factors that influence on their bespoke suit purchase intentions. Accordingly, this work intends to construct a basic environment for consumers to approach the custom suit market easily and pave the way for male suit markets through offering marketing data and information that is helpful for custom suit-related markets.
\end{abstract}

Keywords: bespoke(비스포크), customized suit(맞춤 정장), needs for uniqueness(독특 성추구성형), clothing benefits(의복추구혜택), appearance concern(외모관심)

\section{Introduction}

수많은 정보와 표준화된 상품들이 범람하는 시대에 소비자들은 자신이 원하고 필요한 정보를 스스로 탐색하는 스마트 컨슈머로서(Boyd \& Ellison, 2007), 타인과

Copyright@2017, The Costume Culture Association. All rights reserved 
달리 독특한 자신만의 개성을 표현하고, 이를 소비를 통해 차별화하는 방법에 더욱 집중하고 있다(Byun \& Byun, 2016; Kim, 2010). 한편, 남성 소비자들의 패션 과 외모에 대한 관심과 투자 또한 그 어느 때보다 두 드러진다. 과거와 달리 남성들은 치열한 경쟁 사회 속에서 외모와 외적 이미지가 자신을 나타내는 새로 운 평가도구인 것으로 인식하고(No, Koh, \& Chung, 2005), 대인접촉이 잦은 현대사회에서 자신의 이미지 를 긍정적으로 심어줄 수 있는 도구로서 패션과 의복 을 이해한다(Choi, 2005; Zhou, Xu, \& Di, 2016). '여 미족', ‘그루밍족' 등으로 불리고 있는 이러한 현대 남성 소비자들은, 외모와 외형의 멋스러움에 대한 높 은 관심, 자신을 가꾸기 위한 아낌없이 투자하며(Kim \& Park, 2014), 의복을 구매하고 착용하는 행동에서 보다 큰 소비 가치와 다양한 상품 혜택을 추구한다 (No et al., 2005).

현대 남성들의 환경과 의식 변화에 따라 타인과 다 른 나만의 상품을 만들기 위한 맞춤 시스템이 남성복 시장의 중요한 화두로 다시 떠오르고 있다. 특히 남 성 정장(suit)은 남성의 사회적, 개인적 지위와 이미지 를 나타내는 대표적인 복종으로, 소비자들의 많은 투 자와 관여가 집중되는 반면(Park, 2010), 일반적 패션 제품에 비해 전통적 드레스코드가 명확하여 트렌드 혹은 개인적 취향에 따라 변경할 수 있는 디자인의 폭이 좁다. 그 결과, 소비자의 개별적 욕구를 만족시 켜줄 수 있는 맞춤(customization) 서비스가 가능한 대표적인 복종이다(Kim, 2004; Zhou et al., 2016). 한 편, 지금까지 전통적인 맞춤 방식은 채촌의 번거로움 과 함께 긴 제작 기간, 그리고 상대적인 높은 소매 가 격 때문에 대중들에게 확산되기 한계가 있던 반면 (Kim, 2010), 최근 20 30대 남성 소비자를 중심으로 비스포크 정장의 단점을 보완한 중저가 비스포크 정 장이나 $\mathrm{MTM}$ (made-to-measure) 정장이 빠르게 확산 중이다(Kim, 2006; Zhou et al., 2016). 디자인 맞춤에 관해 최근 학술적 연구들이 등장하고 있으나, 아직 초창기로 사례 연구(Zhou et al., 2016) 또는 특정 제 품군에 국한되면서(Byun \& Byun, 2016; Lee, 2016; Yoo \& Park, 2016), 아직까지 현재 부상하고 있는 중 저가 맞춤 정장 시장에 대한 소비자 관점에서의 학술 적 연구는 매우 부족한 상황이다.

이에 본 연구는 남성 소비자의 독특성 욕구와 의복
추구혜택, 그리고 외모 관심도 등의 기본적 심리적 변인들이 남성 맞춤 정장 구매의도에 미치는 영향을 실증적으로 분석하고자 하였다. 한편, 이에 앞서 디자 인 맞춤(design customization)과 사이즈 맞춤(size customization) 서비스를 제공하는 국내 남성 맞춤 정 장 시장 및 $1: 1$ 맞춤정장 비스포크 시스템의 현황을 정리하였다. 이를 종합해 맞춤정장 관련 시장에 도움 이 되는 마케팅 자료와 소비자 정보를 제공함으로써 소비자들이 맞춤정장 시장에 쉽게 접근할 수 있는 기 초적인 환경을 구축하고, 남성정장 시장의 기틀 마련 에 기여하고자 한다.

\section{Literature Review}

\section{Clothing benefits}

의복추구혜택(clothing benefits)이란 소비자가 의 복을 구매하고 사용 시 얻고자 하는 제품의 효능에 대한 긍정적인 기대와 결과를 의미한다(Peter \& Olson, 1987). 다시 말해 소비자가 의복 제품을 구매함 으로써 부족한 부분을 충족하고자 하는 심리적 욕구 와 구매 후, 구매 전 단계에서 계획했었던 요인들의 만족이나 불만족, 이전에 기대하지 못했던 새로운 요 인의 등장에 대한 만족감 등을 모두 뜻한다. Peter and Olson(1987)의 연구에 의하면 추구혜택이란 소비 자들이 특정제품의 속성이나 특성에 대해 생각하는 객관적인 개념이라 할 수 있으며, 제품 사용과 관련 해 필요(want)나 욕구(need)를 느끼게 되는 주관적인 보상 또는 속성이라 정의 내렸다. Lai(1995)는 소비자 가 제품을 구매함으로써 얻을 수 있는 혜택을 7가지 속성으로 나누어 연구하였다. 이는 기능적, 사회적, 정서적, 지적, 미적, 쾌락적 혜택이며, 각 속성들은 상 호관련이 있어 소비활동에 따라 결합되어 나타난다 고 주장하였다. 하지만 이는 모든 소비과정에서 나타 나는 사항은 아니며, 소비자의 의식적, 무의식적 구매 과정에 따라 사라지거나 존재한다고 설명했다.

남성 소비자의 의복 추구혜택은 일반 소비자가 의 복 제품을 구매하는 과정에서 기대하거나 얻을 수 있 는 혜택을 설명한다는 점은 동일하나, 남성과 여성이 동일한 의복제품에 추구하는 혜택이 상이해, 남성만 을 위한 제품일 경우에는 남성소비자의 추구혜택을 파악하여, 그들의 요구를 충족시켜줄 제품을 제공해 
야 한다. 성별의 차이에 따라 동일한 의복에 대한 추 구혜택을 연구한 선행연구를 살펴보면 다음과 같다: 20 대 남성은 타인에게 호감을 줄 수 있는 추구혜택에 높은 관여를 하고 있으며, 다른 연령대 남성소비자들 과 달리 독특함과 개성을 추구하는 성향이 높은 것으 로 나타났다. 30 대 남성들 역시 호감추구, 개성추구의 추구혜택이 높게 나타나면서 젊은 세대일수록 자신 의 인상을 향상시키고, 호감을 줄 수 있는 의복 구매 의도가 높은 것을 알 수 있다. 20 30대 남성 소비자 의 구매의도를 높이기 위해선 독특하고 개성적인 소 비자의 욕구를 충족시켜줄 수 있는 적절한 마케팅이 필요한 현실이다(Cho, 2011). Lee(2007)는 성역할 정 체성과 의복추구혜택을 중심으로 20 40대 남성의 외 모관리 행동의 동기에 관한 연구를 하였는데, 의복추 구혜택의 차원을 심미성 추구, 유행성 추구, 동조성 추구, 사회적 안정 추구, 편안함 추구, 개성 추구, 경 제력 과시 7 가지로 구성하였다. 유행성, 편안함, 개성 추구는 여성성과 정적 상관관계를 보였으며, 심미성 추구는 남성성과 불일치 관계를, 사회적 인정 추구는 부적 상관관계를 보였다. 남성들은 의복에서 유행성, 동조성, 개성이 높을수록 외모관리를 많이 하며, 이는 남성 소비자들의 미의식 또한 변화하고 있다는 결과 를 도출해 내었다.

본 연구에서 알아보고자 하는 남성정장 추구혜택 에 관련된 선행논문들을 살펴보면 $\operatorname{Kang}(1994)$ 은 추 구혜택을 심미성, 실용성, 직업 안정성 3 가지 요인으 로 구분하여 연구한 결과 심미성 추구혜택을 소비자 들이 가장 높게 인식하고 있음을 밝혔으며, 실용성 추구혜택보다 심미성 추구혜택에 더 중시하는 경향 을 보인다고 설명했다. $\mathrm{Kim}(1999)$ 의 연구 또한 성인 남성의 남성정장을 맞춤복, 시스템오더, 기성복으로 구분하여 소비자들의 추구혜택을 연구하였는데, 3 가 지 각각 다른 생산방식의 정장을 구매한 소비자들은 $\operatorname{Kang}(1994)$ 논문의 결과와 같이, 심미성 추구혜택에 유의한 차이가 있음을 밝혀냈으며, 이중 맞춤복을 이 용하는 소비자들이 시스템오더, 기성복을 이용하는 소비자들보다 심미성 추구혜택이 높은 것으로 나타 났다. 즉, 남성에게 사회생활에서의 의복이란 사회적 지위와 직업을 나타내는 단서중 하나로 여겨진다. 자 신의 직위, 외모에 어울리는 의복을 선택하는 것은 자신의 능력 수행에 긍정적인 효과로 작용하는 동시
에, 자기 이미지 표현에도 도움을 줄 수 있는 도구의 하나로 생각하기 때문이다(Shin, 2001). 이상의 선행 연구결과 및 본 연구 주제를 바탕으로, 본 연구에서 는 '유행성 추구(trend pursuit)', '심미성 추구(aesthetics pursuit)', '사회적 지위 추구(social status pursuit)', '편의성 추구(convenience pursuit)', 그리고 '개 성 추구(personal characteristics pursuit)' 등 총 5 가지 의 추구혜택이 비스포크 정장 구매에 연결되는지를 파악했다.

\section{Needs for uniqueness}

Snyder and Fromkin(1980)은 독특성 욕구(need for uniqueness)를 자기만의 독특성과 고유성을 다른 사 람들과 구별되게 표현하려는 비순응적인 개인의 욕 구, 또는 대중으로부터 특별하고자 독특함을 추구해 스스로를 나타내려는 행동이라 정의했다. 이는 자신 을 나타내는 도구 중 하나인 의복을 통해 자신의 독 특함을 표현하고자 하는 욕구와는 달리 본질적으로 내, 외형적인 행동을 통해 욕구를 표출함으로써 대중 과 다른 자신만의 독특성을 추구하려는 성질이다. 독 특성(uniqueness)의 사전적인 의미는 특별하게 다른 성질이란 뜻과 다른 것과 견줄 수 없을 정도로 뛰어 난 성질이란 뜻을 지닌다. 욕구란 무엇을 얻거나, 무 슨 일을 하고자 바라는 심리적 갈망이다. 즉, 독특성 욕구란 타인과 다른 특별함을 원하는 욕구와 뛰어난 자신만의 개성을 추구하려는 경향을 기초로 하는 행 동을 의미한다. Tian, Bearden, and Hunter(2001)는 소비자가 개인적이고 사회적인 이미지를 형성하기 위해 타인과 상대적인 차별성을 추구하려 제품을 획 득하고 사용, 처분하는 행위의 욕구라 정의했다. 선행 연구를 통한 독특성 욕구 정의를 종합해 보면 독특성 욕구는 개성과 달리 다른 사람과의 동조성을 피하고, 자신만의 독특함과 고유성을 표현하려는 심리적 욕 구를 충족시키는 행동이며, 이를 통해 자신의 자존감 을 향상시킴으로써 느끼는 만족감과 편안함으로 볼 수 있다. Snyder(1992)는 소비행동이 개인의 독특성 욕구를 가장 확연히 표출할 수 있는 적절한 분야라 생각했으며, Grubb and Grathwohl(1967)은 소비하는 상품들과 소비자의 개념에 관한 연구를 진행한 결과, 소비자는 자신의 사회적 이미지 또는 가치관을 향상 시키는데 자신의 개성을 가장 잘 표현할 수 있는 상 
품을 소비한다는 것을 증명하였다.

소비자의 독특성 이론은 독특성 욕구 이론과 소비 행동의 여러 문헌 고찰을 통해 Tian et al.(2001)이 크 게 3 가지의 요인으로 구분해 구성하였다. 첫 번째, 소 비자가 자신만의 창의적인 생각과 독창적인 선택을 통해 스타일을 창조하는 행동인 '독창적 선택의 역 순응(creative choice counter conformity)'이다. 두 번 째, 집단의 규범을 벗어난 소비를 하거나 비 대중적 인 제품 선택을 추구하며, 이를 통해 타인과 구별되기 를 원하는 '비 대중적 선택 역 순응(unpopular choice counter conformity)'이다. 마지막으로, 이미 대중에게 널리 전파되어 고유의 특색과 희소성의 가치가 사라 진 제품에 대해 소비욕구를 잃어버리고, 소유하고 있 는 제품일 경우 더 이상 사용하지 않게 되는 '유사성 의 회피(avoidance of similarity)'이다. 독특성 욕구가 높은 소비자들은 소비자 유형 중 모방성이 높은 소비 자들의 선택이 자신의 독특성을 감소시킨다는 위협 을 느끼고 있으며(Fisher \& Price, 1992), 이러한 모방 때문에 더욱더 대중적이지 않으면서 유사성이 없는 독특한 스타일을 추구하려 적극적인 소비행동을 보 이고 있다.

\section{Appearance concern}

외모관심(appearance concern)이란 자신의 외모에 대해 인식하는 소비자의 개인적 주관적 성향이다 (Goffman, 1951). 각종 SNS의 보편화 및 정보화 사회 의 발달로 사람과 사람 사이의 거리가 가까워진 요즘 다른 사람과 구별되고, 나만의 개성을 표현하고 싶은 욕구는 빼놓을 수 없는 본능 중 하나로 여겨지고 있 는 현재이다. 현대인들은 더 이상 외모관리에 소홀할 수 없는 상태이며, 이는 원만한 대인관계를 위한 필 수요소로 여겨지고 있다. 또한 개인의 능력을 평가하 는 하나의 잣대로 기준되기도 하며, 사회적 인식 또 한 진실된 내면의 모습보단 꾸며진 외적인 모습에 더 큰 영향을 받을 수 있다(Noh, 2014). 외모의 사전적 정의는 外(밖 외)貌(모양 모)로써 언어적 해석대로 밖 으로 드러나는 모습을 뜻한다. 외모란 단순히 겉으로 들어나는 얼굴의 형태만을 의미하는 것은 아니며, Kaiser(1996)의 연구에 의하면 자신을 타인에게 인식 시키는 수단중 하나로 전체적으로 보이는 신체적, 시 각적인 모습뿐만이 아닌 비언어적 행동, 표정, 성격
등도 포함되며, 그중에서도 신체와 의복에 의해 가장 영향을 받는 것이라 정의했다. Goffman(1951)은 자신 을 다른 사람에게 보일 때 자신이 생각하고 원하는 모습을 보여주기 위해 의복, 화장품, 소품 등을 사용 하는 행위를 의미하고, 이러한 도구들은 개개인의 이 미지를 관리하는데 이용되므로 정체성 도구라 명명 했다. 인간은 본능적으로 타인보다 외모적으로 뛰어 나길 원하는 욕구를 가지고 있다. 스스로 자신의 외 모를 변화시키는 행동을 통해 자존감을 얻고, 사회적 으로 인정받을수록 높은 만족감을 느낀다. 즉, 타인에 게 가장 먼저 보여지는 외모를 통해 자신의 개성을 표현하고, 이로 인한 다양한 혜택을 얻을 수 있기에 외모관심도는 우리 사회에서 가장 중요한 요소 중 하 나로 여겨지고 있는 현실이다(Lim, Hwang, Lee, \& Lee, 2009). 과거와 달리 외모가 하나의 자기 경쟁력 으로 떠오르면서 자신의 외모를 향상시키는데 도움 이 되는 정보를 적극적으로 찾고 행동하는 행위인 외 모관심도 역시 많은 사람들의 화두로 떠오르게 되었 다. $\operatorname{Kim}(2011)$ 의 연구에 의하면 남성들의 외모 관심 도가 높아지는 이유는 외모를 향상시켜줄 수 있는 미 용과 패션에 대한 관리가 자신의 상품가치를 높이는 중요한 수단이며, 외모 또한 하나의 경쟁력이라는 인 식이 자리 잡았기 때문이라고 그 이유를 설명했다.

남성들의 경우, 치열한 경쟁사회 안에서 타인과 다 른 자신만의 개성을 표현하고 싶은 열망을 가지게 되 었으며, 이에 관심과 투자 또한 아끼지 않게 되었다. '여미족'이라는 신조어까지 등장하게 되었으며, ‘그루 밍족’이라는 새로운 남성 소비층 또한 생겨났다. 타 인과 구분되는 자신만의 영역을 구축하고자 하는 남 성들의 욕구는 외모와 더불어 뷰티, 미용, 패션 등 외 형적으로 드러나는 자신의 모든 것에 대해 다방면으 로 높은 관여를 하게 되었다. 과거로부터 여성성의 상징이며, 여성의 문화로 이해되었던 외모관심도는 여성 주도적인 행위로 인식되어 왔지만, 남성의 높은 외모관심이 사회 전반적으로 자연스러운 문화의 흐 름으로 이해되고, 경제상황이 안정됨에 따라 성별에 따른 역할, 의식 또한 변화되어 남, 여의 구분 없이 인간에게 중요시 되고 있는 욕구의 하나로 받아들여 지고 있는 추세이다(Kim, 2014). 남성들의 외모에 대 한 관심이 과거에는 부끄럽고 여성스러운 행동의 하 나라 여겨 남성성을 저해시키는 행동으로 인식했었 
다면 요즘엔 자신의 가치를 높이는 행동중 하나이고, 타인과 자신을 구별 지을 수 있는 가장 쉬우면서 효 과적인 방법이란 인식이 유행에 민감한 젊은 남성들 을 대상으로 급속도로 퍼지고 있는 상황이다. Hansen and Hansen(1988)은 외모는 모든 사람들에게 자신의 이미지를 보여주는 것으로, 나이가 어릴수록 자신에 대한 판단력이 부족하기에 성인보다 더 많은 외모관 심도를 가지고, 외부의 자극에 큰 영향을 받게 된다 고 설명했다. 특히 학창시절 바쁜 학업과 한정적인 라이프스타일로 인해 외모 관리의 필요성을 인식하 지 못하다가, 사회적으로 안정을 찾아가는 성인이 된 후, 늘어난 자기관리 시간과 치열한 경쟁사회에서 타 인과 구분되며, 자신을 돋보이게 할 수 있는 수단으 로 외모를 인식하는 젊은 세대의 변화된 가치관이 실 제 패션 시장에 영향을 미치고 있다.

\section{Customized suits}

맞춤(customization)의 사전적 정의를 살펴보면 특 정한 개인의 주문에 따라 원하는 대로 만든다는 동사 customize의 명사형으로 주문제작, 맞춤제작의 의미 를 지니고 있다. 많은 사람들이 개인화(personalization)와 비슷하거나 같은 의미로 오인하고 있는데, 개 인화는 판매 주체가 특정 소비자의 정보와 과거 행 동, 구매 이력을 기반으로 분석해, 소비자에게 맞는 마케팅 메시지를 전달하여 수동적으로 받아들이는 행동을 의미한다면 맞춤(customization)은 반대로 소 비자가 능동적으로 자신에게 맞는 상품을 찾아 제작 및 구매를 한다는 것을 뜻하며, 행동의 주체가 판매 자인지 소비자인지에 따라 다르게 이해해야 하는 부 분이다(Lee, 2016). 선행논문을 통한 맞춤의 정의로 Chun(2003)은 주문자의 요구와 공급과정의 상황을 고려해 사양, 기능을 조정하는 것이라 정의했다. 그는 주문자의 무리한 요구는 소비자 편의를 위해 개발된 맞춤 시스템에 문제를 초래할 것이라 생각했으며, 특 히 눈에 보이지 않는 분야의 맞춤 시스템에선 비효율 적인 결과를 야기할 수 있음을 예상했다.

맞춤에 관련된 선행 논문들을 알아본 결과, 맞춤이 란 주문자와 생산자의 구별이 명확하고, 주문자의 특 성과 편리함을 위한 능동적 의견이 생산자의 생산품 에 영향을 미치는 제작 과정이라 종합해 볼 수 있다. 남성의복 분야에서 대표적으로 맞춤이 가능한 의
복으론 남성정장이 있으며, 국내 남성정장은 생산방 식에 따라 대량 주문 생산된 기성정장과 소량 맞춤 생산된 맞춤정장으로 구분할 수 있다. 기존의 기성정 장은 공업진흥청 표준안에 따른 20 30가지 유형의 치수를 기준으로 평균화된 8 개의 치수가 전체 남성정 장 치수 중 $60 \sim 70 \%$ 정도를 차지하고 있어 맞음새와 관련된 부분은 소비자의 욕구를 완벽히 충족시켜주 지 못하고 있는 현실이다(Kim, 1991). Kim(1996)의 연구에 의하면 소비자는 기성정장의 전체적 맞음새 에 큰 불만을 느끼지는 않지만, 연령 및 체형별 신체 부위 맞음새를 조사한 결과, 대상자 중 절반 정도만 만족하고 있는 것으로 나타났다. 특히 20 대의 경우에 는 소매길이와 목둘레가 작음을 느끼고 있었는데, 이 는 서구화 체형으로 변화함에 따른 현상으로 볼 수 있다고 하였다. 남성정장을 연구한 선행연구 결과, 소 비자들은 특히 기성정장의 맞음새에 대한 불만족을 느끼고 있었으며, 이러한 욕구를 만족시켜줄 수 있는 제품이 소비자 개인의 신체사이즈를 토대로 제작되 는 맞춤정장이라 인식하고 있었다. 이처럼 다양한 고 객의 체형을 보완해 주지 못하는 단점을 가진 기성정 장의 경우, 맞음새와 더불어 외모관리를 통해 자신의 멋과 독특성을 표현하고 싶어 하는 남성들에게 만족 스러운 의복혜택을 주지 못하고 있다. 이에 20 30대 남성 소비자들은 자신의 신체와 체형, 의견을 반영해 제작되는 맞춤정장에 높은 관심을 가지기 시작했다. 이에 발맞춰 맞춤정장 시장도 변화하는 소비채널과 정보통신 산업의 흐름에 따라 기존 가두상권 형태에 서 웹/모바일을 기반으로 간편하게 즐길 수 있는 온 라인 기반의 구매채널이 등장함에 이르렀다. $\mathrm{O} 2 \mathrm{O}$ (Online to Offline) 플랫폼을 활용해 적극적인 마케팅 으로 불특정 다수의 고객을 유입하고, 바쁜 현대인을 위해 간편히 예약, 방문이 가능한 고객맞춤 서비스는 맞춤정장 시장이 나아가야 할 새로운 지향점을 제시 하고 있다(Kim, 2016).

〈Table 1〉과 같이 남성정장에서 맞춤의 범주 안에 는 크게 1:1 맞춤인 '비스포크(bespoke)'와 대량맞춤 인 'MTM(made-to-measure)'으로 분류할 수 있다. 각 각은 옷의 기본이 되는 패턴이 고객 개별사이즈에 의 해 제작되는지, 표준화된 패턴을 기준으로 수정되는 지에 따라 구분할 수 있는데, 서로 다른 과정으로 인 해 장단점을 가지고 있으며, 소비자들은 자신이 중요 
<Table 1> Types of customized suits

\begin{tabular}{|c|c|c|c|c|c|c|}
\hline & \multicolumn{6}{|c|}{ Customization } \\
\hline & \multicolumn{3}{|c|}{ 1:1 Customization } & \multicolumn{3}{|c|}{ Mass-customization } \\
\hline Examples & \multicolumn{3}{|c|}{ Bespoke } & \multicolumn{3}{|c|}{ MTM (Made-to-measure) } \\
\hline $\begin{array}{l}\text { Construction } \\
\text { types }\end{array}$ & $\begin{array}{c}\text { Full } \\
\text { canvas }\end{array}$ & Half canvas & $\begin{array}{l}\text { Fully } \\
\text { fused }\end{array}$ & System-order & Size-order & Easy-order \\
\hline $\begin{array}{l}\text { Pattern-making } \\
\text { process }\end{array}$ & \multicolumn{3}{|c|}{$\begin{array}{c}\text { 3D/2D pattern-making based on customer's } \\
\text { individual sizes }\end{array}$} & \multicolumn{3}{|c|}{ Patternmaking based on standardized size } \\
\hline
\end{tabular}

시하는 사항이 무엇인지 정확히 파악한 후에 구매혜 택을 얻을 수 있는 맞춤정장을 선택할 권리를 가진 다. 남성정장은 다른 의복에 비해 전통적으로 정형화 된 스타일과 디자인을 가지고 있는 특성으로 인해 소 비자의 취향에 따라 변경될 수 있는 디자인의 폭이 좁아 주문되는 의복을 제작하는데 다른 복종보다 수 월하다는 것을 장점으로 가지고 있다. 또한 캐주얼 디자인의 의복들과 달리 정확한 맞음새가 요구되는 의복이기에 맞춤제작 서비스가 필요한 의복으로 여 겨져 소비자들의 많은 관심을 받고 있다(Kim, 2004). 정통 맞춤정장의 개념은 영국식 비스포크로부터 시 작되며, 일반적으로 숙련된 전문 테일러가 고객의 요 구에 따라 고객만을 위해 제작하는 남성정장으로 이 해된다. 이러한 비스포크 정장 제작방식은 테일러가 직접 고객의 습관이나 행동을 파악하기 위한 소통으 로부터 시작한다. 사이즈를 직접 채촌한 뒤 신체에 따라 완성되는 패턴에 고객이 직접 원단 및 각종 부 자재 선택과 세부 디자인, 특히 맞음새를 결정할 수 있다는 점에서 완벽한 디자인, 사이즈 맞춤이 불가능 한 대량맞춤 MTM과 차이를 둔다. 즉, 비스포크 정장 제작과정은 높은 수준의 $1: 1$ 맞춤이란 의미를 가지 며, 이는 곧 모든 제작과정에 소비자가 직접 의견을 제시하고 관여할 수 있다는 것을 뜻한다.

비스포크 공정과정에 따른 분류를 보면 '비접착식 (full canvas)', '반 비접착식(half canvas)', '접착식 (fully fused)' 등 3 가지로 나누어진다. 이 중에 ‘비 접 착식(full canvas)' 공정과정은 정통 비스포크가 추구 하는 과정이다. 우리나라에선 '게싱'이라 불리는 캔버 스(canvas)가 어깨에서부터 가슴과 전면부위에 접착 되지 않고 떠 있는 상태로 팔자 뜨기 손바느질(padstitching)을 통해 원단과 연결되는 것을 의미한다. 고
객의 주된 행동과 움직임에 따라 활동성이 많은 부위 에 연결되어 있는 canvas의 바느질 방향이 시간이 지 날수록 착용자의 신체에 맞게 완벽히 변형되어 최적 의 편안함을 제공한다. 반 비 접착식 공정과정은 비 접착식 공정과정과 유사하나, canvas의 크기와 체형 을 감싸는 범위가 절반 정도로 어깨부터 앞 가슴부분 의 라펠 시작점까지이며, 비 접착식 과정보다 저렴한 가격과 단축된 제작기간이 장점이다. 접착식 공정과 정은 가장 대중화된 대표적 비스포크 공정방식이며, 기성정장과 비스포크정장의 장점이 적절히 접목되어 많은 소비자들에게 선호되는 과정이다. 정통 비스포 크 제작과정에서 가장 오랜 시간과 많은 비용이 들어 가는 캔버스(canvas)가 생략된 방식이며, 가슴 앞판의 형태를 유지하기 위해 전면으로 접착식 심지(fusible) 가 사용된다. 열처리 가공으로 쉽고 간편하게 공정을 진행할 수 있으며, 최근 급성장하고 있는 중저가 비 스포크 시장에서 주로 채택하고 있는 추세이다.

\section{Methods}

\section{Research model and questions}

본 연구에서 알아보고자 하는 독특성 욕구와 의복 추구혜택이 비스포크 정장 구매의도에 미치는 영향, 의복추구혜택이 비스포크 정장 구매의도에 미치는 영향과 외모 관심도가 조절변수로 작용했을 때의 차 이를 알아보기 위한 실증 분석을 위해 다음과 같은 연구문제를 설계하였다. 연구모형은 〈Fig. 1〉과 같다.

연구문제 1. 의복추구혜택이 비스포크 정장 구매의 도에 미치는 영향을 알아본다.

연구문제 2. 독특성 욕구가 비스포크 정장 구매의 


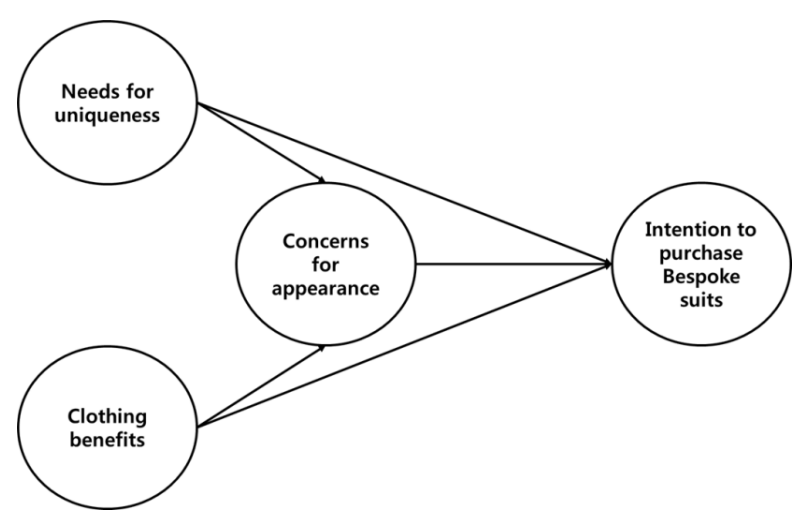

<Fig. 1> Research model

도에 미치는 영향을 알아본다.

연구문제 3. 의복추구혜택과 비스포크 정장 구매의 도 간 관계에서 외모 관심도의 조절효 과를 알아본다.

연구문제 4. 독특성 욕구와 비스포크 정장 구매의 도 간 관계에서 외모 관심도의 조절효 과를 알아본다.

\section{Main study}

본 연구는 다른 연령층에 비해 외모 관심도와 독특 성 욕구가 비교적 높은 전국의 20 30대 남성 중 단 한 번이라도 남성정장 구매경험이 있는 소비자들을 대상으로 실시하였다. 예비조사를 바탕으로 조사자들 이 이해하기 어려운 비스포크 정장의 정의와 관련된 문항을 수정, 보완한 후 2015년 4월 28일부터 5월 3 일까지 구글(Google Form)의 모바일, 웹페이지용 전 자 설문지 방식을 사용하여 진행되었다. 최종적으로 총 370 부가 회수되었으며, 이 중 불성실하고 불완전 한 응답이나 본 연구에 해당되지 않는 9부를 제외한 후, 총 361 부를 본 연구의 최종분석 자료로 사용하였 다. 수집된 표본을 통한 연구문제를 분석하기 위해 SPSS 22.0을 사용하여 실증연구를 실시하였다.

설문문항은 각 변수별 관련 선행연구들(Noh, 2014; Park, 2011)의 문항을 바탕으로 본 연구의 상황에 맞 게 소폭 조정하여 사용하였다. 남성정장구매행동은 구매 시 동반자, 구매 빈도, 구매 가격, 구매 시기 등 총 4문항, '남성 소비자 독특성 욕구는 옷을 구매하는 이유는 나의 개성을 표현해줄 수 있는 무언가를 찾는 것이라 생각한다.' '나는 가끔씩 좀 더 독특한 나만의 이미지를 창출하기 위해서 특이한 옷이나 브랜드를
구매한다' 등의 15 문항, 의복추구혜택은 '나는 옷을 입을 때 멋있어 보이도록 노력한다', '나는 옷을 잘 입음으로써 다른 사람들에게 좋은 인상을 주려고 노 력한다, 등의 24 개 문항을 사용해 측정했다. 남성 소 비자 외모 관심도는 '나는 내 외모가 남들에게 어떻 게 보이는지 신경을 쓰는 편이다.' 등 10 문항을, 마지 막으로 비스포크 정장 구매 의도는 총 4 개의 문항을 이용하여 측정했다. 설문지는 6가지 영역으로 구성되 어 있으며, 첫째, 조사자의 인구 통계적 특성, 둘째, 남성 소비자의 정장 구매행동, 셋째, 남성 소비자의 독특성 욕구, 넷째, 남성 소비자의 외모 관심도, 다섯 째, 남성 소비자의 의복추구혜택, 여섯째, 비스포크 정 장 구매의도 순으로 설문조사를 실시하였다. 인구 통 계적 문항과 남성정장 구매행동에 관한 문항들은 객 관식과 단답형으로 수집하였으며, 독특성 욕구, 외모 관심도, 의복추구혜택, 비스포크 정장 구매의도에 대 한 각 문항별 척도는 5점 리커트(Likert) 척도로 평가 를 실시하였다. 각 요인별 주성분 요인분석방법에 의 한 탐색적 요인분석을 실시한 결과, 독특성 욕구(독 창성 선택, 유사성 회피, 비대중적 선택 등 3 개 요인 의 총 누적분산 $67.33 \%$ ), 의복추구혜택 요인(유행추 구, 심미성 추구, 사회적 지위 추구, 편안함 추구, 개 성 추구 등 총 5 개 요인의 총 누적분산 $65.61 \%$ )으로 나타났으며, 외모관심도와 구매 의도는 각각 단일차 원요인으로 분석되었다. Cronbach's Alpha값은 독특 성 욕구 각 요인마다 .84 .90, 의복추구혜택은 각 요인 마다 .79 .89, 외모관심도 .87, 구매의도 .91로 나타나, 설문문항의 기본적 신뢰도와 타당도가 확인되었다.

\section{N. Results}

\section{Correlation analysis}

본 연구의 연구문제를 알아보는데 사용할 변수인 남성 소비자 의복추구혜택, 독특성 욕구의 요인분석 과 상관관계 분석을 토대로 비스포크(bespoke)정장 구매의도에 미치는 영향력을 알아보기 위한 다중회 귀분석(multiple regression analysis)을 실시했으며, 그 결과는 다음과 같다.

남성 소비자 의복추구혜택이 비스포크 정장 구매 의도에 미치는 영향을 알아보기 위해 요인분석을 통 한 다중회귀분석을 실시한 결과(Table 2$), R^{2}=.14$, 전 
$<$ Table 2> Effect of clothing benefits on purchase intention of bespoke suit

\begin{tabular}{|c|c|c|c|c|c|c|}
\hline Independent variables & $\mathrm{B}$ & $\beta$ & $t$ & $R^{2}$ & $\Delta R^{2}$ & $\Delta F$ \\
\hline Trend pursuit & -.01 & -.01 & -.15 & \multirow{5}{*}{.14} & \multirow{5}{*}{.13} & \multirow{5}{*}{$11.91^{* *}$} \\
\hline Aesthetics pursuit & .27 & $.22^{* *}$ & 3.36 & & & \\
\hline Social status pursuit & .12 & .11 & 1.71 & & & \\
\hline Convenience pursuit & .08 & .07 & 1.32 & & & \\
\hline Personal characteristics pursuit & .12 & .11 & 1.90 & & & \\
\hline
\end{tabular}

Durbin-Watson=2.01

${ }^{*} p<.05,{ }^{* *} p<.01,{ }^{* * *} p<.001$

체 변동의 $14 \%$ 로 회귀모형을 확인할 수 있었다. 남성 소비자의 의복추구혜택 중 '심미성 추구' $(\beta=.22, p<$ $.01)$ 가 비스포크 정장 구매의도에 유의함을 알 수 있 었다. 분석과정에서 잔차의 영향으로 인해 발생할 수 있는 오류를 검증하는 Durbin-Watson Test 값은 기준 수치인 2에 근접한 2.01 로 회귀식에 잔차는 존재하지 않으며 독립성이 충족되었다.

〈Table 3〉의 남성 소비자 독특성 욕구 요인이 비스 포크정장 구매의도에 미치는 영향을 알아보기 위해 요인분석을 통한 다중회귀분석을 실시한 결과 $R^{2}=.07$ 로 전체 변동의 $7 \%$ 로 회귀모형을 확인할 수 있었다. 남성 소비자의 독특성 욕구 요인 중 '비 대중적 선택' 을 제외한 '독창적 선택' $(\beta=.23, p<.001)$, ‘유사성 회 피 선택' $(\beta=.12, p<.05)$ 이 비스포크 정장 구매의도에 유의함이 확인되었다.

〈Table 4〉와 같이 의복추구혜택에 따른 비스포크 (Bespoke)정장 구매의도의 관계에서 외모관심도의 조절효과 검증을 위해 Baron and Kenny(1986)가 제 시한 위계적 조절회귀분석(moderated regression analysis)을 실시했으며, 결과는 다음과 같다.
단계 1을 살펴보면 비스포크(Bespoke)정장 구매의 도에 영향을 미치는 의복추구혜택 요인으로는 '심미 성 추구 $(\beta=.22, p<.01)$ '가 유의한 것으로 나타났다. 단계 2 의 외모관심도가 투입된 경우 의복추구혜택 요 인 중 '심미성 추구 $(\beta=.21, p<.05)$ '만 유의한 것으로 나타났으며, 외모관심도는 구매의도에 유의한 영향을 미치지 않는 것으로 나타났다. $\Delta R^{2}$ 은 통계적으로 증 가하였고, $F$ 값의 변화량은 유의하지 않았다 $\Delta F=$ $.00, p>.05)$. 상호작용 변수가 투입된 3 단계 회귀분석 결과, 외모관심도는 의복추구혜택 요인 중 '유행 추 구'( $\beta=.23, p<.05)$, '심미성 추구' $(\beta=.23, p<.05)$ 와 구 매의도의 관계에 정(+)적으로 유의하게 나타났으며, '사회적 지위 추구' $(\beta=-.21, p<.05)$ 에는 부(-)적으로 유의하게 나타났다. 상호작용 효과에 대한 $\Delta R^{2}$ 은 $6 \%$ 증가한 것으로 나타났으며, $F$-변화량은 통계적으 로 유의하게 나타났다( $\Delta F=5.64, p<.001)$.

〈Table 5 〉의 독특성 욕구 요인과 구매의도의 관계 에서 외모관심도 조절효과의 단계 1 을 살펴보면 비스 포크(Bespoke)정장 구매의도에 영향을 미치는 독특 성 욕구 요인으로는 '독창적 선택' $(\beta=.23, p<.001)$ 과

$<$ Table 3> Effect of need for uniqueness on purchase intention of bespoke suit

\begin{tabular}{c|c|c|c|c|c|c}
\hline \multicolumn{1}{c|}{ Independent variables } & $\mathrm{B}$ & $\beta$ & $t$ & $R^{2}$ & $\Delta R^{2}$ & $\Delta F$ \\
\cline { 1 - 3 } Creative choice counter conformity & .23 & $.23^{* * *}$ & 3.55 & & & \multirow{2}{*}{.07} \\
\cline { 1 - 3 } Avoidance of similarity & .12 & $.12^{*}$ & 2.05 & .06 & $9.47^{* * *}$ \\
\cline { 1 - 3 } Unpopular choice counter conformity & -.10 & -.09 & -1.46 & & & \\
\hline
\end{tabular}

Durbin-Watson=1.97

${ }^{*} p<.05,{ }^{* *} p<.01,{ }^{* * *} p<.001$ 
$<$ Table 4> Moderation effect of appearance concern on the effect of clothing benefits on purchase intention of bespoke suit

\begin{tabular}{|c|c|c|c|c|c|c|}
\hline Steps & Independent variables & $\mathrm{b}(S E)$ & $\beta$ & $R^{2}$ & $\Delta R^{2}$ & $\Delta F$ \\
\hline \multirow{5}{*}{1} & Trend pursuit & $-01(.08)$ & -.01 & \multirow{5}{*}{.14} & \multirow{5}{*}{.14} & \multirow{5}{*}{$11.81^{* * *}$} \\
\hline & Aesthetics pursuit & $.27(.08)$ & $.22^{* *}$ & & & \\
\hline & Social status pursuit & $.12(.07)$ & .11 & & & \\
\hline & Convenience pursuit & $.08(.06)$ & .06 & & & \\
\hline & Uniqueness pursuit & $.12(.06)$ & .11 & & & \\
\hline \multirow{6}{*}{2} & Trend pursuit & $-.01(.08)$ & -.01 & \multirow{6}{*}{.14} & \multirow{6}{*}{.00} & \multirow{6}{*}{.00} \\
\hline & Aesthetics pursuit & $.27(.10)$ & $.21^{*}$ & & & \\
\hline & Social status pursuit & $.12(.07)$ & .11 & & & \\
\hline & Convenience pursuit & $.08(.06)$ & .06 & & & \\
\hline & Personal characteristics pursuit & $.12(.06)$ & .06 & & & \\
\hline & Appearance concern & $.00(.10)$ & .00 & & & \\
\hline \multirow{11}{*}{3} & Trend pursuit & $-.08(.08)$ & -.06 & \multirow{11}{*}{.20} & \multirow{11}{*}{.06} & \multirow{11}{*}{$5.64^{* * *}$} \\
\hline & Aesthetics pursuit & $.36(.10)$ & $.28^{* * *}$ & & & \\
\hline & Social status pursuit & $.14(.07)$ & .13 & & & \\
\hline & Convenience pursuit & $.10(.06)$ & .08 & & & \\
\hline & Personal characteristics pursuit & $.14(.06)$ & $.13^{*}$ & & & \\
\hline & Appearance concern & $.03(.10)$ & .02 & & & \\
\hline & Trend pursuit $\times$ Appearance concern & $.31(.12)$ & $.23^{*}$ & & & \\
\hline & Aesthetics pursuit $\times$ Appearance concern & $.29(.11)$ & $.23^{*}$ & & & \\
\hline & Social status pursuit $\times$ Appearance concern & $-.27(.11)$ & $-.21^{*}$ & & & \\
\hline & Convenience pursuit $\times$ Appearance concern & $.09(.07)$ & .07 & & & \\
\hline & $\begin{array}{l}\text { Personal characteristics pursuit } \\
\times \text { Appearance concern }\end{array}$ & $-.13(.10)$ & -.10 & & & \\
\hline
\end{tabular}

'유사성 회피 선택' $(\beta=.14, p<.05)$ 이 유의한 것으로 나타났다. 단계 2의 외모관심도가 투입된 경우, 독특 성 욕구 요인 중 ‘독창적 선택' $(\beta=.14, p<.05)$ 과 외모 관심도 $(\beta=.18, p<.01)$ 가 유의한 것으로 나타났으며, $\Delta R^{2}$ 은 통계적으로 증가하였고, $F$-변화량은 유의하 게 나타났다 $(\Delta F=9.38, p<.01)$. 단계 3의 상호작용 변 수가 투입된 회귀분석 결과, 외모관심도는 독특성 욕 구 요인 중 ‘독창적 선택' $(\beta=.21, p<.01)$ 과 구매의도 의 관계에 정 $(+)$ 적으로 유의하게 나타났으며, '비 대
중적 선택' $(\beta=-.15, p<.05)$ 에는 부(-)적으로 유의하게 나타났다. 상호작용 효과에 대한 $\Delta R^{2}$ 은 $3 \%$ 증가한 것으로 나타났으며, $F$-변화량은 통계적으로 유의하게 나타났다 $(\Delta F=4.21, p<.01)$.

\section{Conclusion}

\section{Summary and discussion}

본 연구의 연구문제를 바탕으로 비스포크 정장 구 
$<$ Table 5> Moderation effect of appearance concern on the effect of need for uniqueness on purchase intention of bespoke suit

\begin{tabular}{|c|c|c|c|c|c|c|}
\hline Steps & Independent variables & $\mathrm{b}(S E)$ & $\beta$ & $R^{2}$ & $\Delta R^{2}$ & $\Delta F$ \\
\hline \multirow{3}{*}{1} & Creative choice counter conformity & $.23(.06)$ & $.23^{* * *}$ & \multirow{3}{*}{.07} & \multirow{3}{*}{.07} & \multirow{3}{*}{$9.47^{* * *}$} \\
\hline & Avoidance of similarity & $.12(.06)$ & $.14^{*}$ & & & \\
\hline & Unpopular choice counter conformity & $-.07(.07)$ & -.09 & & & \\
\hline \multirow{4}{*}{2} & Creative choice counter conformity & $.14(.07)$ & $.14^{*}$ & \multirow{4}{*}{.09} & \multirow{4}{*}{.02} & \multirow{4}{*}{$9.38^{* *}$} \\
\hline & Avoidance of similarity & $.10(.06)$ & .10 & & & \\
\hline & Unpopular choice counter conformity & $-.09(.07)$ & -.07 & & & \\
\hline & Appearance concern & $.24(.08)$ & $.18^{* *}$ & & & \\
\hline \multirow{7}{*}{3} & Creative choice counter conformity & $.14(.07)$ & $.13^{*}$ & \multirow{7}{*}{.12} & \multirow{7}{*}{.03} & \multirow{7}{*}{$4.21^{* *}$} \\
\hline & Avoidance of similarity & $.10(.06)$ & .10 & & & \\
\hline & Unpopular choice counter conformity & $-.06(.07)$ & -.05 & & & \\
\hline & Appearance concern & $.28(.08)$ & $.20^{* *}$ & & & \\
\hline & $\begin{array}{l}\text { Creative choice counter conformity } \\
\times \text { Appearance concern }\end{array}$ & $.24(.08)$ & $.21^{* *}$ & & & \\
\hline & Avoidance of similarity $\times$ Appearance concern & $.04(.09)$ & .03 & & & \\
\hline & $\begin{array}{l}\text { Unpopular choice counter conformity } \\
\times \text { Appearance concern }\end{array}$ & $-.21(.09)$ & $-.15^{*}$ & & & \\
\hline
\end{tabular}

매의도에 영향을 주는 요인과 변수 간 관계를 실증 분석한 결과는 다음과 같다.

의복추구혜택이 비스포크 정장 구매의도에 미치는 영향을 살펴본 결과, '심미성 추구’만이 구매의도에 영향을 주는 것으로 확인되었다. 소비자는 비스포크 정장을 구매함으로써 얻을 수 있는 다른 혜택들보다 알맞은 맞음새로 외형상 보기 좋고 기성복과 다른 미 적, 디자인적 멋스러움을 추구하는 것으로 해석할 수 있다. 독특성 욕구가 비스포크 정장 구매의도에 미치 는 영향으로는 ‘독창적 선택'과 ‘유사성 회피 선택’이 구매의도에 영향을 주는 것으로 확인되었다. 소비자 가 직접 맞춤 제작과정에 참여하면서 독창적인 스타 일을 창조하려는 욕구를 가지거나, 자신의 의견과 신 체사이즈를 기초로 세상에 단 한 벌뿐이라는 희소성 의 가치를 중요하게 생각할수록 비스포크 정장 구매 의도가 높은 것으로 이해할 수 있다.

의복추구혜택과 비스포크 정장 구매의도 관계에서 외모관심도의 조절효과를 알아본 결과, '유행성'과
‘심미성'을 추구하는 소비자에게 외모관심도가 반영 됐을 때, 비스포크 정장 구매의도에는 정(+)적인 영향 을 미치는 것을 알아볼 수 있었다. 누구보다 최신유 행을 즉시 반영하고 선도하길 추구하며, 보기 좋고 멋스러운 제품을 원하는 소비자가 외모와 외적 이미 지도 중요시 생각한다면 다른 어떤 정장을 착용했을 때보다 맞춤이라는 소비자 주도적 주문과정을 통해 높은 만족감을 얻을 수 있는 비스포크 정장 구매의도 가 더 높을 것으로 이해할 수 있다. 반면, '사회적 지 위'를 추구하는 소비자에게 외모관심도가 반영됐을 때 비스포크 정장 구매의도는 부(-)적인 것을 확인할 수 있었다. 외모, 외형에 많은 관심과 함께 사회적 지 위를 추구하는 소비자는 타인에게서 자신을 인정받 을 때 높은 만족감을 얻는다. 이들은 아무리 최고급 비스포크 정장을 착용하고 있어도 다수의 사람들이 옷의 가치를 인식해 주지 못한다면 상대적으로 대중 적인 명품이나 유명 브랜드를 착용했을 때보다 낮은 만족감을 얻을 수밖에 없다. 이는 곧 이들의 사회적 
이미지 우려로 인해 비스포크 정장 구매의도가 높지 않다는 것으로 판단해 볼 수 있다.

독특성 욕구와 비스포크 정장 구매의도 관계에서 외모관심도의 조절효과를 알아본 결과, '독창적 선택' 을 하는 소비자에게 외모관심도가 반영됐을 때 비스 포크 정장 구매의도에는 정 $(+)$ 적인 영향을 미치는 것 을 알아볼 수 있었다. 독창적인 스타일을 창조하길 원하는 소비자가 외모와 외적 이미지도 중요시 생각 한다면 비스포크 정장 구매의도가 더욱 높을 것으로 사료된다. 반면, '비 대중적 선택'을 하는 소비자에게 외모관심도가 반영됐을 때는 비스포크 정장 구매의 도에 부(-)적인 영향을 미치는 것을 확인할 수 있었 다. 소비자가 추구하는 대중의 기준에서 타인과 구별 되길 원해 더욱 대중적이지 않는 제품을 원하거나, 남성정장이란 의복을 이미 다수의 사람들이 즐기는 대중적인 제품으로 인식하고 있을 경우, 구매의도는 높지 않을 것으로 생각해볼 수 있다.

\section{Implications}

본 연구의 결론을 통한 학문적 의의는 다음과 같 다. 독특성 욕구의 선행논문을 살펴보면 욕구 정도에 따른 소비자 행동의 차이를 분석한 연구가 주를 이루 고 있다. 그러나 본 연구는 독특성 욕구 요인을 기준 으로 요인별 차이를 분석해 독특성 욕구를 가진 소비 자들의 의복추구혜택 특성을 규명하는 연구를 실시 하였다. 또한 외모관심도의 경우, 미용, 뷰티에 관련 된 관리행동 연구가 대부분이었으며 외모관심 정도 에 따른 의복구매행동을 분석한 연구는 거의 없는 실 정이다. 과거와 달리 20 30대 남성은 외모에 대한 높 은 관심과 경제적 능력을 기초로 의복구매행동에 높 은 관여를 하지만, 이를 대상으로 진행한 연구는 미 비한 상황이다. 이에 이들의 독특성 욕구와 외모관심 도에 대한 이론적 배경을 정리함으로써 추후 연구에 대한 자료를 제공함에 높은 의의를 가진다. 또한 본 연구의 주된 이론적 배경인 $1: 1$ 맞춤정장 비스포크의 경우, 산업기술의 발달로 등장한 기성정장과 대량 맞 춤정장에 밀려 이론적, 실증적 연구가 다양하게 이뤄 지지 않고 있는 현재이다. 그러나 전통과 기술력을 바탕으로 명맥을 이어오는 일부 비스포크 정장 브랜 드들과 새로운 소비플랫폼을 활용하여 맞춤정장의 대중화에 앞장 서는 $\mathrm{O} 2 \mathrm{O}$ 전문 브랜드들이 우후죽순
등장하면서 소비자들은 해당산업에 대한 올바른 정 보와 경험을 원함에 이르렀다. 이에 1:1 맞춤 정장인 비스포크를 중심으로 맞춤정장의 정의와 시장 현황 에 대해 알아보고, 비스포크와 대량맞춤(MTM)의 공 정방식 차이를 비교하는 과정을 통해 앞서 자세히 연 구되지 않았던 맞춤정장의 이론적 배경을 정리하는 데 의의를 가진다.

본 연구를 통한 비스포크 정장과 맞춤정장 시장의 마케팅적 시사점은 다음과 같다. 맞춤정장의 가장 큰 강점인 고객의 신체 사이즈와 체형을 토대로 제작, 수정되어 기성정장보다 편안한 착용감을 제공한다는 것은 대부분의 소비자가 기본적으로 인식하고 있는 부분이다. 이는 구매의도를 가지고 맞춤과정에 관여 하는 소비자에게 그 이상의 매력적인 요소로 작용하 지 않고, 당연하게 얻어야 할 혜택 중 하나로 여겨진 다. 이에 특히 완벽한 맞음새를 자랑하는 비스포크 정장의 경우, 변화하는 체형과 유행에 뒤쳐지지 않도 록 연구, 개발에 아낌없는 투자를 하여 전문지식과 고도의 기술을 갖출 수 있도록 노력하고 숙련된 테일 러가 직접 고객과 소통하고 의견을 반영하여 최고의 제품을 완성할 수 있다는 점을 홍보할 수 있도록 한 다. 또한 외형적인 모습이 중요한 소비자의 경우, 한 눈에 기성정장과 구별될 수 있는 디자인을 원한다는 것을 알 수 있다. 이에 기존정장에선 사용하지 않는 독특한 소재나 컬러를 제공해 소비자가 직접 다양한 디자인 맞춤을 진행할 수 있는 맞춤정장만의 장점을 강조해 제작과정의 즐거움이 공유될 수 있도록 되어 야 할 것이다.

대부분의 소비자들은 맞춤정장의 제작과정과 비 용, 관련정보에 쉽게 접할 수 없는 현재이다. 맞춤정 장 브랜드 역시 잘못된 정보를 소비자에게 무분별하 게 제공하고 있기에 정보의 혼돈을 가져다 줄 수 있 으며, 이는 맞춤정장 시장의 성장에 좋지 않은 영향 을 미칠 수 있다. 투명한 제작과정과 올바른 정보를 소비자들이 접근하기 쉽게 제공하여 관련 산업이 의 복시장에 정착하는데 도움이 되는 마케팅을 진행해 야 할 것이다.

또한 일부 남성 소비자는 의복구매의 즐거움을 느 껴보지 못했으며, 자신에게 어울리는, 자신이 선호하 는 스타일에 대한 확신을 갖지 못하는 경우가 많다. 이러한 소비층의 구매욕을 자극하기 위해 다양하고 
이해하기 쉬운 제품 홍보자료를 준비하고, 언제 어디 서나 고객의 소비욕구를 충족시키기 위해 컨설팅이 가능한 환경을 구축해야 할 것이다.

한편, 소비자가 기성정장보다 맞춤정장 구매를 주 저하는 이유인 상대적으로 높은 비용과 오랜 제작기 간은 지속적으로 가지고 가야 할 대표과제이다. 이를 해결하기 위한 방안으로 맞춤정장 브랜드들은 고유 의 역사와 이력에 대한 홍보와 함께 브랜드만의 아카 이브를 구축해 나가 유명 브랜드 못지않은 가치의 의 복을 소비자에게 제공할 수 있다면 소비자는 만족감 과 자부심을 토대로 높은 구매의도를 가질 것으로 예 측되며, 이에 대한 추가적인 실무적 연구와 전략 수 립이 필요하다.

\section{Limitations and suggestion for future research}

현대 남성 소비자들의 독특성 욕구나 외모관심도 와 같은 미의식의 변화는 과거와 달리 특정 계층만 즐기는 행동이 아닌 자신의 개성을 나타내고, 영역을 구축하려는 모든 남성들의 욕망이자 높은 욕구로 발 전해 가고 있다. 미의식을 향상시키는데 가장 일반적 접근방법인 의복을 구매하고 착용하는 행동을 통해 남성 소비자들은 타인과 구별되어지길 바라지만, 남 성 의복 중 남성정장은 아직까지 다른 복종에 비해 착용 시 주어지는 특수한 상황과 이미지가 고려되어 천편일률적인 디자인으로 소비자에게 공급되고 있는 상황이다. 이에 기성정장과 디자인적 차별성을 두고 소비자의 능동적인 의견과 체형을 토대로 제작되는 맞춤정장을 본 연구의 주된 주제로 삼았으나 과거로 부터 이어져 내려오는 전통적인 이미지와 대중적이 지 못한 마케팅을 이유로 다양한 세대의 공감을 얻고 있지 못하고 있는 실정이다. 이에 후속 연구를 위한 제언은 다음과 같다.

본 연구는 독특성 욕구와 외모관심도를 주된 변수 로 설정하였기에 다른 연령층보다 높은 독특성과 외 모관심도를 가진 20 30대 남성을 대상으로 연구를 실시하였다. 남성정장의 경우, 늦어지는 취업시기와 군대, 유학 및 어학연수 등을 이유로 구매연령은 높 아지고 있으며, 실질적인 구매능력을 가진 남성 소비 자층이 30 40대 임을 고려했을 때 이들을 대상으로 하는 연구가 이루어지거나, 전 연령을 대상으로 하는
연구가 진행되어야 할 필요가 있다

본 연구는 첫 번째 한계점과 유사한 이유로 20 대 와 직업이 학생인 조사자가 대부분을 차지하였다. 이 들은 앞으로 활발한 경제활동과 더불어 사회의 중심 구성원 역할을 통해 높은 남성정장 구매의도를 가질 것으로 예상되지만, 현재는 제한점을 가지고 있기에 조금 더 다양한 직업을 가진 조사자를 대상으로 연구 가 진행되어야 할 필요가 있다.

본 연구는 맞춤정장 중 $1: 1$ 맞춤정장인 비스포크를 중심으로 연구를 진행하였다. 맞춤의 의미는 동일하 지만, 전통적인 방식을 고수하며, 소비자의 의견이 $100 \%$ 반영되는 비스포크 정장과 달리 산업화 시대의 발전으로 혁신적인 공정과정을 통해 대량맞춤 생산 을 의미하는 MTM 정장의 경우, 과거와 달리 실용적 인 소비자를 중심으로 점차 주목을 받고 있는 현재이 다. 이에 비스포크 정장과 MTM 정장을 비교하며 분 석하는 연구가 진행되어야 할 필요가 있다.

또한 본 연구는 남성 맞춤 정장에 대한 소비자들의 기본적 심리 변인들의 영향력을 중점적으로 분석한 반면, 후속 연구에서는 소비자들이 남성 맞춤 정장의 디자인 및 제작 과정의 참여에서 체험하는 심리적 효 용과 가치(Lee, 2016), 그리고 기술적 가능성(Byun \& Byun, 2016; Yoo \& Park, 2016) 등에 대해서도 탐구 해 볼 수 있다.

마지막으로, 본 연구의 설문조사 대상자를 모두 과 거정장구매경험이 있는 남성 소비자로 한정하였긴 하지만, 추후 소비자들의 비스포크 정장구매경험에 대한 연구를 진행하려면 정장구매경험을 넘어서 비 스포크 정장구매경험을 가진 소비자들을 대상으로 보다 세밀한 조사가 이루어져야 할 것이며, 이 경우 정확한 모집단의 특성을 정의하고 설문 응답를 등 피 험자에 대한 보다 정확한 정보의 제공이 연구결과의 신뢰성과 타당성을 높이는 데 기여할 것이다.

\section{References}

Baron, R. M., \& Kenny, D. A. (1986). The moderator -mediator variable distinction in social psychological research: Conceptual, strategic, and statistical considerations. Journal of Personality and Social Psychology, 51(6), 1173-1182. doi:10.1037/ 
$0022-3514.51 .6 .1173$

Boyd, D. M., \& Ellison, N. B. (2007). Social network sites: Definition, history, and scholarship. Journal of Computer-Mediated Communication, 13(1), 210-230. doi:10.1111/j.1083-6101.2007.00393.x

Byun, H. J., \& Byun, T. H. (2016). Forecasting and analysis of customized shoes design in domestic and overseas brands. Journal of the Korea Contents Association, 16(1), 382-390. doi:10.5392/ JKCA.2016.16.01.382

Cho, Y. J. (2011). The influence of male consumers' clothing benefits sought on purchase intention of functional clothing: Focused on well-being health consciousness and age. Fashion \& Textile Research Journal, 13(6), 900-908. doi:10.5805/ KSCI.2011.13.6.900

Choi, T.-Y. (2005). An empirical study on the brand pattern choices and customer's satisfaction upon buyer's characteristics of male formal dresses. Unpublished doctoral dissertation, Dong Eui University, Busan, Korea.

Chun, W. J. (2003). Efficient account receivables customizing model on SAP R/3 system. Unpublished master's thesis, Sogang University, Seoul, Korea.

Fisher, R. J., \& Price, L. L. (1992). An investigation into the social context of early adoption behavior. Journal of Consumer Research, 19(3), 477486. doi:10.1086/209317

Goffman, E. (1951). Symbols of class status. The British Journal of Sociology, 2(4), 294-304. doi: $10.2307 / 588083$

Grubb, E. L., \& Grathwohl, H. L. (1967). Consumer self-concept, symbolism and market behavior: A theoretical approach. Journal of Marketing, 31 (4), 22-27. doi:10.2307/1249461

Hansen, C. H., \& Hansen, R. D. (1988). Finding in the crowd: An anger superiority effect. Journal of Personality and Social Psychology, 54(6), $917-$ 924. doi:10.1037/0022-3514.54.6.917

Kaiser, S. B. (1996). The social psychology of clothing: Symbolic appearances in context (2nd
Rev. ed.). New York: Fairchild.

Kang, J. H. (1994). A study on men's ready-made clothes brand recognition about benefits. Unpublished master's thesis, Yonsei University, Seoul, Korea.

Kim, C. I. (2006, July 26). 맞춤양복도 중저가 시대 [Mid-priced customized suits are in trend]. $M K$ Economics, Retrieved on March 16, 2015, from http://news.mk.co.kr/newsRead.php?year=2006\& no $=332448$

Kim, C. S., \& Park, M. R. (2014). A study on the appearance care behaviors, clothing selection behaviors and clothing design preference of 20 30 's Korean men by the level of grooming. $\mathrm{Fa}$ shion \& Textile Research Journal, 16(2), 245254. doi:10.5805/SFTI.2014.16.2.245

Kim, H. J. (2010). Study on the fashion trend of contemporary men's wear since 1990. Fashion Business, 14(5), 78-92.

Kim, H. T. (2016). O2O를 넘어 온디맨드로: 일상생 활로 확대되는 고객 서비스의 진화 [On demand over O2O(Online to Offline)]. Seoul: e bizbooks Press.

Kim, N.-H. (1999). The comparative study of men's custom suits, system order, and ready-made suits: Centering around choice of information source, risk perception, and benefit sought. Unpublished master's thesis, Sungkyunkwan University, Seoul, Korea.

Kim, S.-H. (1991). A study on the actual condition of the domestic ready-made men's suit industry: with priority given to the business suit. Unpublished master's thesis, Sookmyung Women's University, Seoul, Korea.

Kim, S. R. (2004). A study on the on-line sales of mass customized clothes. Design Forum 21, 7, $165-172$

Kim, S.-Y. (2011). Study of $N$-generation male's beauty consumption trend. Unpublished master's thesis, Sookmyung Women's University, Seoul, Korea. 
Kim, S. Y. (2014). A study on skin health care behavior and adult men's concern level for appearance. Unpublished master's thesis, Gachon University, Gyeonggi-do, Korea.

Kim, Y. M. (1996). Consumer's attitude toward size system and fit of men's ready-made business suit. Unpublished master's thesis, Kyung Hee University, Seoul, Korea.

Lai, A. W. (1995). Consumer values, product benefits and customer value: A consumption behavior approach. Advances in Consumer Research, 22(1), 381-388.

Lee, E.-J. (2016). How perceived cognitive needs fulfillment affect consumer attitudes toward the customized product: The moderating role of consumer knowledge. Computers in Human Behavior, 64, 152-162. doi:10.1016/j.chb.2016.06.017

Lee, Y.-J. (2007). Male consumers' motives of appearance management behavior: Focused on their sex role identities and benefit sought in clothing. Journal of the Korean Society of Clothing and Textiles, 31(4), 551-562. doi:10.5850/JKSCT.2007. 31.4 .551

Lim, S. J., Hwang, S. J., Lee, J. N., \& Lee, S. H. (2009). The social psychology of clothing. Seoul: Suhaksa.

No, J. Y., Koh, A. R., \& Chung, M. S. (2005). A study on development of fashion orientation scale for the on-line image consulting of career men. Journal of the Korean Society of Clothing and Textiles, 29(1), 58-67.

Noh, J. E. (2014). A study on effects of male's interest in appearance on self-esteem and job stress. Unpublished master's thesis, Gachon University, Gyeonggi-do, Korea.

Park, S. J. (2011). Influences of consumers' need for uniqueness on clothing purchasing behavior. Un- published master's thesis, Ulsan University, Ulsan, Korea.

Park, Y.-H. (2010). A study on the selection behavior and the post-purchase satisfaction for men' s suits. Fashion \& Textile Research Journal, 12(1), 4659. doi:10.5805/KSCI.2010.12.1.046

Peter, J. P., \& Olson, J. C. (1987). Consumer behavior: Marketing strategy perspectives. New York: Irwin Professional Publishing.

Shin, S. Y. (2001). A study on the shopping orientation, importance of store attributes, and selfimage according to the clothing benefits of the adult males of twenties and thirties. The Research Journal of the Costume Culture, 9(6), 818-829.

Snyder, C. R. (1992). Product scarcity by need for uniqueness interaction: A consumer catch-22 carousel? Basic and Applied Social Psychology, 13 (1), 9-24. doi:10.1207/s15324834basp1301_3

Snyder, C. R., \& Fromkin, H. L. (1980). Uniqueness: The human pursuit of difference. New York: Plenum Press.

Tian, K. T., Bearden, W. O., \& Hunter, G. L. (2001). Consumers' need for uniqueness: Scale development and validation. Journal of Consumer Research, 28(1), 5-66. doi:10.1086/321947

Yoo, J., \& Park, M. (2016). The effects of e-mass customization on consumer perceived value, satisfaction, and loyalty toward luxury brands. Journal of Business Research, 69(12), 5775-5784. doi:10. 1016/j.jbusres.2016.04.174

Zhou, Y., Xu, M., \& Di, R. (2016). Research on the radical innovation of $\mathrm{C} 2 \mathrm{M}$ business model: $\mathrm{A}$ case study on Redcollar MTM men's suits in China. International Journal of Business and Management, 11(4), 194-202. doi:10.5539/ijbm. v11n4p194 